\title{
The Impact Role of Childhood Traumas and Life Events in Patients with Alopecia Aerate and Psoriasis
}

Ismail Volkan Şahiner*, Nilgun Taskintuna, Ali Emre Sevik, Ozlem Karadag Kose, Hatice Atas, Safak Sahiner and Sedat Isikli

Oncology Education and Research center Ankara, Turkey

*Corresponding author: Ismail Volkan Şahiner, Oncology Education and Research center Ankara, Turkey, Tel: 905053675921; E-mail: volkansahiner@gmail.com

Received Date: August11, 2014, Accepted Date: September 23, 2014, Published Date: September 30, 2014

Copyright: (c) 2014, Ismail Volkan Şahiner et al., This is an open-access article distributed under the terms of the Creative Commons Attribution License, which permits unrestricted use, distribution, and reproduction in any medium, provided the original author and source are credited.

\begin{abstract}
Background: Alopecia areata (AA) and psoriasis are common dermatological diseases which may be associated with psychosomatic origin. Close relationship with stressful life events has been shown both AA and psoriasis in previous studies. Dermatologic diseases which are thought to be psychosomatic origin are not examined about childhood traumas except AA. In the literature there is no study that investigates both stressful life events with childhood trauma in healthy indiviudals and dermatological diseases with psychosomatic origin such as AA and psoriasis.
\end{abstract}

Objective: To determine whether stressful life events and childhood traumas play a role in AA is the first aim of this study. If it is, will this role specific for AA as a second aim? The patients with psoriasis and healthy individuals were also investigated too.

Methods: Patients (range: 18-70 years of age) with a diagnosis of AA and psoriasis who admitted to Dermatology Outpatient Department of Baskent University Medical Faculty between August 2009 and July 2010 were recorded and analyzed for our study. Healthy individuals without past or present psychiatric symptoms proven by the Composite International Diagnostic Interview (CIDI) as control group were selected randomize. Forty patients with AA, 30 patients with psoriasis, and 50 healthy subjects as controls were stratified as three individual groups. The Childhood Trauma Questionnaire, the Life Events Checklist, The Beck Depression Inventory, and the Beck Anxiety Inventory and socio demographic data questionnaire were administered to the participants. Informed consent was obtained from all participants.

Results: The rate of childhood traumatic events, the stressful life events, anxiety and depression scores were significantly higher in both $\mathrm{AA}$ and psoriasis group than healthy controls. Significant difference was not found between $A A$ and psoriasis patients.

Conclusion: Childhood traumas and stressful life events may play a role in the pathogenesis of AA. In addition, this role may also apply to other psychosomatic diseases as psoriasis. This result may let us understand the role of past and present psychological stressors in the etiology of dermatologic psychosomatic diseases. Psycho dermatologic new approaches are needed to evaluate stressful life events and childhood traumas.

Keywords: Alopecia areata; Psoriasis; Childhood trauma; Psychosomatic disease; Life events

\section{Introduction}

Alopecia areata (AA) is a dermatological condition that characterized by asymptomatic, well-defined patches of non-scarring alopecia that affects the scalp in approximately $90 \%$ of cases. AA is the most common cause of localized, non-scarring alopecia. Its prevalence is estimated around $1.7 \%$ [1]. It may first appear in childhood or later. The cause of AA is not fully understood, but immunologic and endocrine abnormalities, genetic disorders, infections, psychological stress factors are believed to play a part in the etiology of AA [2]. Wars, torture, political or non political violence, family problems, rape, sexual abuse, accidents and natural disasters are some of the causes of psychological and physical traumas. People are usually get involved to some stressful conditions and frustrations. In normal conditions, those may not lead any developmental problems, but in severe cases, according to the person's age, self power, genetics, and socioeconomic status those stressful conditions or frustrations may lead to chronic psychiatric disorders.

The role of psychological factors in AA has long been a subject of debate, with various investigators reporting contradictory findings regarding the rates of psychopathology in patients with this condition, as well as the role of psychological events or stress in the onset of symptoms [2-4]. The role of lifetime events and childhood traumas has also been the focus of attention in AA patients, but there is only very limited number of reports about these two subjects [1,3,4]. To investigate the relationship of childhood traumas and stressful lifetime events with AA and psoriasis is purpose of our study with the comparison of healthy controls. Life events which occurred in the last one year are only included by previous studies with AA and psoriasis, but not childhood traumatic events. Our hypotheses was exposing to childhood traumas and stressful lifetime events more often in AA than healthy subjects physically and psychologically. However, this is not specific to AA patients. 


\section{Materials and Methods}

\section{Subjects}

Approval for this study was obtained from the ethical committee of the Baskent University Medical Faculty. Patients (range 18-70 years of age) who admitted to the Department of Dermatology Outpatient Clinic, Baskent University Medical Faculty between August 2009 and July 2010 with a diagnosis of AA and psoriasis were included in this study. Literacy, mental capacity and answer to the test questions were other requirements for inclusion to this study. Healthy individuals without past or present psychiatric symptoms proven by the Composite International Diagnostic Interview (CIDI) were included to study, randomize $[5,6]$. Study groups were stratified as 40 patients with AA, 30 patients with psoriasis, and 50 healthy subjects as controls. Informed consent was obtained. All data about age, gender, duration of illness etc. recorded.

\section{Methods}

Socio demographic data questionnaire and Clinical Information Form and CIDI (anxiety and depression parts) which were filled by the investigator were administered to participated subjects. In addition, the Childhood Trauma Questionnaire [7], the Life Events Checklist [8], The Beck Depression Inventory [9], and the Beck Anxiety Inventory [10] were administered to all participants, too.

\section{Beck Depression Inventory (BDI)}

The BDI is a 21-item self-report inventory. Some of the items are related to symptoms of depression, while others are related to physical concerns such as sleep disturbances, loss of weight, etc. Other items investigate emotional (degrees of hopelessness, sorrow), motivational (willingness to work), and cognitive (concentration, self evaluation) aspects of life. Each question is rated from 0 to 3 points. The sum of the points shows the level of depression. The 1979 version of the BDI [11] is adapted for the Turkish population by Hisli $[12,13]$. The cut-off point was 17. BDI score over 17 points was defined as "Definite depression" in our study.

\section{Beck Anxiety Inventory (BAI)}

The BAI is a 21-item self-report inventory. The questions gather information about physical (feeling shaky, butterflies in the stomach), cognitive (being afraid something terrible will happen, fear of losing control), and emotional (feeling tense, angry) aspects of the individual's life in this survey. The BAI is adapted for the Turkish population by Ulusoy et al. [10,14].

\section{Childhood Traumatic Questionnaire}

Childhood Traumatic Questionnaire is a 53-item self-report. It is developed by Bernstein and associates in 1994 [15]. The questions are about events experienced during childhood and adolescence. It has been translated into Turkish by Sar [16].

\section{Life Events Scale (LES)}

Life events were recorded according to a major life events inventory by Sorias [17]. The inventory covers 116 major life events, in which every life event has two different scores, namely standard adjustment and distress scores. Each life event is thus scored on two dimensions. Higher scores indicate a higher stress level. In our study, patients were asked to record the events which had occurred during the 6 months prior to the onset of AA, psoriasis and healthy controls.

\section{Composite International Diagnostic Interview (CIDI)}

The CIDI is a comprehensive, fully-structured interview which is designed to be used by trained lay interviewers for the assessment of mental disorders according to the definitions and criteria of ICD-10 and DSM-IV. It is intended for use in epidemiological and crosscultural studies as well as for clinical and research purposes. The diagnostic section of the interview is based on the World Health Organization's Composite International Diagnostic Interview (WHO CIDI, 1990). In this study we used anxiety and depression parts.

\section{Statistical Analysis}

Analysis was performed using SPSS 16.0 for Windows. In analysis, the scores which calculated by using CIDI Anxiety and Depression Section, CTQ, LES, BAI, BDI were evaluated as separate outcome variables. Whether the three different sample groups in study group have differences or not, in terms of the various measurements was questioned by the One Way ANOVA. $\mathrm{P}<0.05$ was evaluated as significant statistically. Independents variables were stated as normally-healthy, Alopecia Areata and Psoriasis. Dependent variables were the total points determined from CTQ, LES, BAI, and BDI. In post hoc analysis, Turkey test was applied.

\section{Results}

A total of 122 subject (55 (45\%) male (M) and 67 (55\%) female, M/F: 0.82) were recorded and analyzed. Forty-one subjects in AA, 31 subjects in psoriasis, and 50 subjects in control groups were evaluated. Mean ages were $32.9 \pm 10.5$ in AA group, $42.1 \pm 14.8$ in psoriasis group, and $35 \pm 13.8$ in control group. Females comprised 51\%, 55\%, and $58 \%$ of the AA, psoriasis, and controls, respectively. Significant difference was not found between groups according to age and gender. When the groups were investigated for substance abuse, smoking was similar in all 3 groups (between 32-37\%). Alcohol consumption was higher in psoriasis group (20\%). Alcohol consumption and smoking was similar in all 3 groups. There were no statistical differences between groups (Table 1).

The duration of the disease varied for AA and psoriasis group. The disease lasted longer than 5 years in $75 \%$ of the psoriasis patients whereas it was $14.6 \%$ in AA group. $63 \%$ of AA patients had their disease less than a year. Aesthetically non-disturbance was $9.7 \%$ in psoriasis group and $2.4 \%$ in AA group. $46.3 \%$ of AA patients and $22.6 \%$ of psoriasis patients were heavily disturbed aesthetically (Table 2). All 3 groups demonstrated statistically significant difference for mean depression scores $(\mathrm{F}(2,119)=13.6 \mathrm{p}<0.05$. Mean depression points were not statistically significant between AA and psoriasis groups (Table 3 ). Mean anxiety scores were statistically significantly different for all 3 groups $\mathrm{F}(2,119)=20, \mathrm{p}<0.05$. There was no statistical significant difference between AA and psoriasis groups (Table 4). 
Citation: Sahiner IV, Taskintuna N, Sevik AE, Kose OK, Atas H, et al. (2014) The Impact Role of Childhood Traumas and Life Events in Patients with Alopecia Aerate and Psoriasis. J Psychiatry 17: 1000162. doi:10.4172/1994-8220.1000162

Page 3 of 6

\begin{tabular}{|l|l|l|l|l|l|l|l|l|}
\hline & \multicolumn{3}{|l}{ Alopecia areata } & \multicolumn{2}{l|}{ Psoriasis } & \multicolumn{2}{l|}{ Healthy } & \multicolumn{2}{l|}{ Total } \\
\cline { 2 - 9 } & $\mathrm{n}$ & $\%$ & $\mathrm{n}$ & $\%$ & $\mathrm{n}$ & $\%$ & $\mathrm{n}$ & $\%$ \\
\hline Smoking & 15 & $36,6 \%$ & 10 & $32,3 \%$ & 17 & $34,0 \%$ & 42 & $34,4 \%$ \\
\hline Alcohol & 3 & $7,3 \%$ & 6 & $19,4 \%$ & 5 & $10,0 \%$ & 14 & $11,5 \%$ \\
\hline Both & 6 & $14,6 \%$ & 3 & $9,7 \%$ & 6 & $12,0 \%$ & 15 & $12,3 \%$ \\
\hline None & 17 & $41,5 \%$ & 12 & $38,7 \%$ & 22 & $44,0 \%$ & 51 & $41,8 \%$ \\
\hline Total & 41 & $100,0 \%$ & 31 & $100,0 \%$ & 50 & $100,0 \%$ & 122 & $100,0 \%$ \\
\hline
\end{tabular}

Table1: Substance abuse for the groups

\begin{tabular}{|l|l|l|l|l|}
\hline & \multicolumn{2}{|l|}{ Alopecia areata } & \multicolumn{2}{l|}{ Psoriasis } \\
\hline Duration & $\mathrm{n}$ & $\%$ & $\mathrm{n}$ & $\%$ \\
\hline$<3$ months & 16 & $39,0 \%$ & 1 & $3,2 \%$ \\
\hline $3-12$ months & 12 & $29,3 \%$ & 2 & $6,5 \%$ \\
\hline $12-24$ months & 1 & $2,4 \%$ & 2 & $6,5 \%$ \\
\hline $2-5$ years & 6 & $14,6 \%$ & 3 & $9,7 \%$ \\
\hline$>5$ years & 6 & $14,6 \%$ & 23 & $74,2 \%$ \\
\hline Location & & & & \\
\hline Scalp & 29 & $70,7 \%$ & 3 & $9,7 \%$ \\
\hline Face & 11 & $26,8 \%$ & 1 & $3,2 \%$ \\
\hline Neck & 1 & $2,4 \%$ & 1 & $3,2 \%$ \\
\hline Arms & - & - & 11 & $35,5 \%$ \\
\hline Legs & - & - & 6 & $19,4 \%$ \\
\hline Back & - & - & 3 & $9,7 \%$ \\
\hline Chest & - & - & 3 & $9,7 \%$ \\
\hline Genitals & 1 & - & - & $0,0 \%$ \\
\hline Other & - & $2,4 \%$ & 3 & $9,7 \%$ \\
\hline Aesthetically disturbance & & $29,3 \%$ & 11 & $35,5 \%$ \\
\hline None & - & $26,8 \%$ & 5 & $16,1 \%$ \\
\hline Mild & 11 & $19,5 \%$ & 2 & $6,5 \%$ \\
\hline Medium & - & & & $3,2 \%$ \\
\hline Severe & - & & & \\
\hline Much severe & & & $32,3 \%$ \\
\hline
\end{tabular}

Table 2: Comparision of alopecia areata and psoriasis groups for the duration of the disease, and aesthetically disturbance.

Childhood Trauma Questionnaire mean scores were statistically significantly different between all 3 groups $\mathrm{F}(2,119)=6.8$, $\mathrm{p}<0,05$. Both in AA group and Psoriasis group CTQ scores were higher than healthy individuals and the differences were statistically significant $\mathrm{p}<0.05$. Mean scores were higher in the AA group compared to psoriasis

group, but did not reach statistical significance (Table 5). There was statistically significant difference between all 3 groups for total LES adjustment scores $\mathrm{F}(2,19)=6.4, \mathrm{p}<0.05$. Mean scores were higher in the AA group compared to psoriasis group, but did not reach statistical significance (Table 6). There was statistically significant difference for mean distress scores between all 3 groups $F(2,119)=8.2$, $\mathrm{p}<0.05$.

\begin{tabular}{|l|l|l|l|l|}
\hline Groups & Mean & SD & Alopecia areata & Psoriasis \\
\hline Alopecia areata & 13.2 & 10.9 & & NS \\
\hline Psoriasis & 10.0 & 7.0 & NS & \\
\hline Control & 4.9 & 3.8 & $p<0.05$ & $p<0.05$ \\
\hline
\end{tabular}

Table 3: Turkey test results for BDI mean scores, NS: Not Significant, SD: Standard deviation, BDI: Beck Depression Inventory

\begin{tabular}{|l|l|l|l|l|}
\hline Groups & Mean & SD & AA & Psoriasis \\
\hline Alopecia areata & 12.8 & 12.9 & & NS \\
\hline Psoriasis & 11.8 & 8.6 & NS & \\
\hline Control & 5.0 & 4.7 & $\mathrm{p}<0.05$ & $\mathrm{p}<0.05$ \\
\hline
\end{tabular}

Table 4: Turkey test results for BAI mean scores. BAI: Beck Anxiety Inventory, NS: Not Significant, SD: standard deviation: alopecia areata

Mean scores were higher in the psoriasis group compared to AA group, but did not reach statistical significance (Table 7). There was no difference between psoriasis and AA groups regarding the results of CIDI. The incidence of active anxiety, depression or depression with anxiety was $41 \%$ in the AA group. It was $22.7 \%$ in the psoriasis group. It was similar in both groups who did not have anxiety or depression. Previous anxiety or depression or depression with anxiety was $33.1 \%$ in the psoriasis group whereas it was $17.1 \%$ in the AA group (Table 8 ).

\begin{tabular}{|l|l|l|l|l|}
\hline Variable & Mean & SD & Alopecia areata & Psoriasis \\
\hline Alopecia areata & 86.9 & 20.7 & - & NS \\
\hline Psoriasis & 83.8 & 27.2 & NS & - \\
\hline Control & 74.8 & 15.3 & $p<0.05$ & $p<0.05$ \\
\hline
\end{tabular}

Table 5: Turkey test results for CTQ mean scores, CTQ: Childhood Trauma Questionnaire, NS: Not Significant, SD: Standard deviation 
Page 4 of 6

\begin{tabular}{|l|l|l|l|l|}
\hline Variable & Mean & SD & Alopecia areata & Psoriasis \\
\hline Alopecia areata & 209 & 22.0 & - & NS \\
\hline Psoriasis & 182 & 25.3 & NS & - \\
\hline Control & 96 & 19.6 & $p<0.05$ & $p<0.05$ \\
\hline
\end{tabular}

\begin{tabular}{|l|l|l|l|l|}
\hline Variable & Mean & SD & Alopecia areata & Psoriasis \\
\hline Alopesia areata & 204,710 & 28,974 & - & NS \\
\hline Psoriasis & 241.039 & 22,814 & NS & - \\
\hline Control & 108,220 & 25,194 & $p<0.05$ & $p<0.05$ \\
\hline
\end{tabular}

Table 6: Turkey test results for mean LES adjustment scores, NS: Not Significant, SD: Standard deviation

Table 7: Turkey test results for mean LES distress scores, NS: Not Significant, SD: Standard deviation

\begin{tabular}{|c|c|c|c|c|c|}
\hline CIDI & & AA $(N=41)$ & Psoriasis $(\mathrm{N}=31)$ & Control $(\mathrm{N}=50)$ & Total $(\mathrm{N}=122)$ \\
\hline \multirow[t]{2}{*}{ None } & N & 17 & 15 & 50 & 82 \\
\hline & $(\%)$ & $41,5 \%$ & $48,4 \%$ & $100,0 \%$ & $67,2 \%$ \\
\hline \multirow[t]{2}{*}{ Active depression } & $\mathrm{N}$ & 3 & 2 & - & 5 \\
\hline & $(\%)$ & $7,3 \%$ & $6,5 \%$ & - & $4,1 \%$ \\
\hline \multirow[t]{2}{*}{ Active anxiety } & N & 2 & 2 & - & 4 \\
\hline & $(\%)$ & $4,9 \%$ & $6,5 \%$ & - & $3,3 \%$ \\
\hline \multirow{2}{*}{$\begin{array}{l}\text { Active depression and } \\
\text { anxiety }\end{array}$} & $\mathrm{N}$ & 12 & 3 & - & 15 \\
\hline & $(\%)$ & $29,3 \%$ & $9,7 \%$ & - & $12,3 \%$ \\
\hline \multirow[t]{2}{*}{ Previous depression } & $\mathrm{N}$ & 7 & 5 & - & 12 \\
\hline & $(\%)$ & $17,1 \%$ & $16,1 \%$ & - & $9,8 \%$ \\
\hline \multirow[t]{2}{*}{ Previous anxiety } & N & - & 2 & - & 2 \\
\hline & $(\%)$ & - & $6,5 \%$ & - & $1,6 \%$ \\
\hline \multirow{2}{*}{$\begin{array}{l}\text { Previous depression } \\
\text { and anxiety }\end{array}$} & $\mathrm{N}$ & - & 2 & - & 2 \\
\hline & $(\%)$ & - & $6,5 \%$ & - & $1,6 \%$ \\
\hline \multirow[t]{2}{*}{ Total } & $\mathrm{N}$ & 41 & 31 & 50 & 122 \\
\hline & $(\%)$ & $100,0 \%$ & $100,0 \%$ & $100,0 \%$ & $100,0 \%$ \\
\hline
\end{tabular}

Table 8: Comparison of the groups with CIDI for the diagnosis of depression and anxiety AA: Alopecia areata

\section{Discussion}

Psychosocial effects of chronic skin disorders have been ignored partially until now. These patients may have a better quality of life if psychiatric co morbidity is defined in a better way and treated appropriately [18]. There are lots of studies about childhood traumatic events which may play a role in dermatological problems. However, this condition has not been investigated in AA patients. Our study's results suggested that childhood traumatic events were significantly more often seen in AA patients compared to healthy control group. This may be related to immunologic mechanisms which may be a cause for AA (19-20) and trauma which may trigger conflict that appears in the form of AA.

Childhood traumas remained as a subject that isn't researched much in AA. Whereas the post-traumatic difficulties in expressing the emotions and having relationships with others and reasons like the lack of social support affect negatively the people's ability to cope stressful life events. By determining the possible psychiatric co morbidity, if the patients can be treated with a biopsychosocial approach it could provide a really positive contribution to the lives of patients. In this study, childhood traumatic events were higher in AA patients compared to psoriasis patients, but statistical significance was not found. These findings may imply childhood traumatic events also may play a role in the etiology of psychodermatosis. The difference of our study compared to previous reports on the AA and childhood traumas did not include other dermatosis as a control group, and these studies did not answer the questions if these findings were peculiar to AA patients only. Earlier studies with AA and psorasis related to previous life events only included life events which occurred in the last one year of the disease, but not the childhood traumatic events. Willemsen and co-workers [4] found that the numbers of life-time and childhood traumatic events were higher compared to healthy controls, but they did not investigate any other dermatosis as a control group. It is debatable that these findings are particular to AA.

The difference between the mean score of people in Alopecia Areata and psoriasis group is higher but insignificant in AA group. This may indicate that the negative effects of childhood traumas also may have a role in the etiology of other psychodermatoses. It's remarkable that there is no another skin disease in use as control group in any of the limited number of studies about the AA and childhood traumas 
before. So, the question of whether the findings are specific to disease could not be answered. Childhood traumatic events are not peculiar to AA and childhood trauma may play a role in the pathogenesis of other dermatosis like psoriasis according to our hypothesis. Our findings supported our hypothesis. Because stressful events during childhood had an effect on the occurence of dermatosis. Previous studies with vitiligo, lichen planus, acne vulgaris, pemphigus, and seborrheic dermatitis are controversial. The role of recent stressful life events in the pathogenesis of psoriasis, AA, atopic dermatitis, and urticaria are more prominent [3]. Only few studies meet the standard methodology. However, our study had a strong study design. Stressful lifetime events may play a major role in the pathogenesis of dermatologic disorders. In our study, childhood traumas and life events distress scores were statistically higher in psoriasis and AA groups compared to healthy individuals.

The effects of lifetime events are controversial in previous studies with the children, and as a control group only healthy individuals are included. Reeve et al found no relation between lifetime events and AA in 12 children [21]. Liakopoulou interestingly did not find any increase in negative lifetime events in children with AA compared to control group, instead there was lack of positive lifetime events [22]. In their study negative lifetime events consisted of trauma, but in our study Childhood Trauma Questionnaire included questions consisting of lackness of positive lifetime events, the difference between 2 studies might be related to this reality. In a different study, stressful lifetime events played a role in $65 \%$ of AA patients. The results of these previous studies were in concordance with our current study.

Stressful life events play a role in the etiology of AA, but this effect is not particular to AA. Previous studies [24-27] investigated stressful life events within last 1 year in AA patients, and the results were statistically significantly more often compared to control group. But, in these studies control group consisted of healthy individuals or patients with other dermatitis. Russiello et al. [28] and Paga et. al. [29] found no difference in stressful life events between AA patients and control groups, but Russiello chose patients with pigmented nevus or keratosis as a control group, and Paga included only 18 women with AA. The reason for the difference in our study might have been attributed to included male and female with AA with a concordence of the frequency. Capoore et al. found $69 \%$ of patients with chronic skin disorders with resistance to therapy had an important life event at the time of their disease [30]. Al Abadie et al. [31] found that psychological stress increases neuroendocrine hormone levels, and as a result immune system was affected and neuropeptide levels were changed. Increase in neuropeptide levels might be the initiative effect in the pathogenesis of AA [31]. By observing negative life events, Gaston et.al.[32] showed psychological stress caused redness of the skin and proved the relationship between psychological stress and difficulties. The lack of life events in the pathogenesis of psoriasis, AA, atopic dermatitis, and urticaria might be attributed to small size of the study group, and these studies are mostly retrograde studies. Our study was different from the above-stated studies because it was prospective; control group consisted of psoriasis patients and healthy individuals, and with a control group of exact number of study subjects. In addition, we investigated stressful life events, childhood traumas, and anxiety and depression concurrently.

When we look at the previous studies for the severity of depression and anxiety, the results are not clear as the diagnosis of depression and anxiety. Severity of anxiety and depression were higher than the control group in their study groups. On the other hand, , Güleç et al.
[2], Yazıcı et al. [19] did not observe any difference for anxiety and depression levels between the control and study groups. This difference may be attributed to scales used in the studies, and to the inaduquate number of study objects for statistical purposes. Since previous studies for comparing AA and psoriasis for the severity of anxiety and depression are limited. We were not able to compare our results with previous studies for comparing the severity of anxiety and depression in AA and psoriasis groups.

Previous studies with AA patients showed a wide spectrum of psychiatric disorders. In a study, Colon [35] found 39\% major depression and $39 \%$ anxiety disorder in AA patients. Fernando et al. [36] found psychiatric symptoms in $77 \%$ of AA patients. Another study by Taskintuna et al. [2] showed that the rate of depression and anxiety disorders were similar in AA and control group whereas stressful life events were more often in AA. Stressful life events and trauma may initiate depression, anxiety or various psychiatric disorders; as a result it has been a matter of question whether these patients' higher depression or anxiety scores were related to AA itself or to stressful life events or childhood trauma. There are new studies telling us that Alopecia areata is associated with poor psychiatric status and quality of life, especially in childhood. The impact of the disease on quality of life occurs through both clinical and psychiatric parameters. Also we know psoriasis markedly worsens the global wellbeing of patients and their cohabitants, who experienced an impairment of their quality of life and higher levels of anxiety and depression.

The difference of our study from the previous studies was that we compared depression and anxiety disorder in AA patients with healthy controls as well as with the psoriasis group as a control group. This was the strength of our study. In addition, we compared all three groups, AA, psoriasis, and healthy controls with each other as well as between AA and psoriasis groups.

\section{To the limitations of our study}

Although our study has got enough samples, having higher numbers could increase the power of research. Another limitation, because of the cultural and religious variables of our country it was difficult to compare, especially in the female patients, due to the place of the lesions appears and changing levels of discomfort. In the patients who have cover for religious reasons, psoriasis in the arms was placed in unseen areas, or the AA in the hair; but the other patients who haven not the same religious clothing, lesions were able to be seen. Naturally, the invisible lesions were both less uncomfortable and disturbing self image for those patients.

\section{Results and Suggestions}

In our study, AA patients were compared in terms of psoriasis patients and healthy control groups, socio-demographic characteristics and severity of anxiety and depression, childhood traumas and life events. All of these variables were significantly higher in AA group, than the healthy control group besides there was no detected significant differences between psoriasis groups. In AA, psoriasis and possibly in other skin diseases, symptoms of anxiety and depression are quite common and interdisciplinary treatment (psychiatry and dermatology) was seen as a necessity for patients to have more benefits from the treatment and for the reduction of recurrence of disease. To ensure that, providing widespread of psycho-dermatology clinics and developing as a separate side branch should be supported. 
The aim of this study is indicating that the psychiatric disorders may have a major role in dermatologic diseases, for the correction of diagnosis and effectiveness of the treatment, the mental illness history of the patient should be considered. The future studies in this area should be directed to research if the childhood traumas and stressful life events are valid for other psycosomatic diseases like peptic ulcer, neudermatitis, migraine, fibromyalgia, hives, vitiligo, asthma. This also will help us to understand more about the role of the spiritual events in the past and present, in the etiology of pathology.

\section{References}

1. Picardi A, Pasquini P, Cattaruzza MS, Gaetano P, Baliva G, et al. (2003) Psychosomatic factors in first-onset alopecia areata. Psychosomatics 44: 374-381.

2. Güleç AT, Tanriverdi N, Dürü C, Saray Y, Akçali C (2004) The role of psychological factors in alopecia areata and the impact of the disease on the quality of life. Int J Dermatol 43: 352-356.

3. Manolache L, Benea V (2007) Stress in patients with alopecia areata and vitiligo. J Eur Acad Dermatol Venereol 21: 921-928.

4. Willemsen R, Vanderlinden J, Roseeuw D, Haentjens P (2009) Increased history of childhood and lifetime traumatic events among adults with alopecia areata. J Am Acad Dermatol 60: 388-393.

5. Witchen HU, Robins LN, Cottler LB, Janca A (1991) Cross-cultural feasibility, reliability and sources of variance of the Composite International Diagnostic Interview (CIDI). Br J Psychiatry 159: 653-658.

6. Kiliç C, Gögüs A. Uluslararasi Bilesik Tani Görüsmesi, 2.1. Hacettepe Üniversitesi Tip Fakültesi Psikiyatri Bölümü Dünya Saglik Örgütü Isbirligi Merkezi, Yayin No:2, Ankara, 1997.(Ingilizceye çevrilmeli)

7. DP Bernstein, L Fink, L Handelsman, J Foote, M Lovejoy, et al. (1994) Initial reliability and validity of a new retrospective measure of child abuse and neglect. Am J Psychiatry 151: 1132-1136.

8. Sorias S (1982) Research of the effects of stressful life events on patients and controls (in Turkish). Thesis Izmir: Ege University, School of Medicine.

9. BECK AT, WARD CH, MENDELSON M, MOCK J, ERBAUGH J (1961) An inventory for measuring depression. Arch Gen Psychiatry 4: 561-571.

10. Beck AT, Epstein N, Brown G, Steer RA (1988) an inventory for measuring clinical anxiety: Psychometric properties. J Consult Clin Psychol 56: 893-97.

11. Jarrett RB, Vittengl JR, Clark LA (2008) How much cognitive therapy, for which patients, will prevent depressive relapse? J Affect Disord 111: 185-192.

12. Hisli N (1988) A study on the validity of the Beck depression inventory. J Psychol 6: 118-122.

13. Hisli N (1989) Validity and reliability of the Beck depression inventory in university students. J Psychol 7: 3-13.

14. Ulusoy M, Sahin NH, Erkmen H (1988) Turkish version of the Beck Anxiety Inventory psychometric properties. J Cognitive Psychother.

15. DP Bernstein, L Fink, L Handelsman, J Foote, M Lovejoy, et al. (1994) Initial reliability and validity of a new retrospective measure of child abuse and neglect. Am J Psychiatry 151: 1132-1136.

16. Sar V. Çocukluk çagi travmalari soru listesi. Istanbul Tip Fak. Psikiyatri Anabilim Dali. (Bu referansin aslini bulamadim).
17. Sorias S (1982) Hasta ve normallerde yasam olaylarinin stres erici etkilerinin arstirilmasi. Ege Üniversitesi, Ege Tip Fakültesi Psikiyatri Bilim Dali, Doçentlik Tezi, Izmir. (Tezler yurt disi yayinda referans olabiliyormu?)

18. Barankin B, DeKoven J (2002) Psychosocial effect of common skin diseases. Can Fam Physician 48: 712-716.

19. Cordan Yazici A, Bå̊Ÿterzi A, Tot Acar S, Ust ̃̃²/4nsoy D, IkizoÄŸlu G, et al. (2006) [Alopecia areata and alexithymia]. Turk Psikiyatri Derg 17: 101-106.

20. Paus R, Arck P (2009) Neuroendocrine perspectives in alopecia areata: does stress play a role? J Invest Dermatol 129: 1324-1326.

21. Reeve EA, Savage TA, Bernstein GA (1996) Psychiatric diagnoses in children with alopecia areata. J Am Acad Child Adolesc Psychiatry 35: 1518-1522.

22. Liakopoulou M, Alifieraki T, Katideniou A, Kakourou T, Tselalidou E, et al. (1997) Children with alopecia areata: psychiatric symptomatology and life events. J Am Acad Child Adolesc Psychiatry 36: 678-684.

23. Manolache L, Oprea C, Benea V (2003) Stress and anxiety involved in alopecia areata. Dermatol Psychosomatics 4: 112-113.

24. Baldaro B, Brocani G, Bossi G, Offidani AM, Novelli N, et al. (1989) Incidenza di eventi stressanti nei sei mesi precedenti la com- parsa di alopecia areata. Med Psicosom 34: 271-275.

25. Perini GI, Veller Fornasa C, Cipriani R, Bettin A, Zecchino F, et al. (1984) Life events and alopecia areata. Psychother Psychosom 41: 48-52.

26. Lyketsos GC, Stratigos J, Tawil G, Psaras M, Lyketsos CG (1985) Hostile personality characteristics, dysthymic states and neurotic symptoms in urticaria, psoriasis and alopecia. Psychother Psychosom 44: 122-131.

27. Invernizzi G, Gala C, Russo R, Polenghi M ve ark (1987) Life events and personality factors in patients with alopecia areata. Med Sci Res 15: 1219-1220.

28. Rusiell F, Arciero G, Decaminada F, Corona R ve ark (1995) Stress, attachment and skin disease: A case control study. J Eur Acad Dermatol Venereol 5: 234-239.

29. Paga G, Faina P, Teodori A, Angelini E ve ark (1992) Gsychological factors in alopecia areata: Results froma preliminary, controlled study, New Trends. Exp Clin Psychiatry 8: 73-79.

30. Capoore HS, Rowland Payne CM, Goldin D (1998) Does psychological intervention help chronic skin conditions? Postgrad Med J 74: 662-664.

31. Al'Abadie MS, Kent GG, Gawkrodger DJ (1994) The relationship between stress and the onset and exacerbation of psoriasis and other skin conditions. Br J Dermatol 130: 199-203.

32. Gaston L, Lassonde M, Bernier-Buzzanga J, Hodgins S, Crombez JC (1987) Psoriasis and stress: a prospective study. J Am Acad Dermatol 17: 82-86.

33. Koblenzer CS (1983) Psychosomatic concepts in dermatology. A dermatologist-psychoanalyst's viewpoint. Arch Dermatol 119: 501-512.

34. Hughes JE, Barraclough BM, Hamblin LG, White JE (1983) Psychiatric symptoms in dermatology patients. Br J Psychiatry 143: 51-54.

35. Colón EA, Popkin MK, Callies AL, Dessert NJ, Hordinsky MK (1991) Lifetime prevalence of psychiatric disorders in patients with alopecia areata. Compr Psychiatry 32: 245-251.

36. Fernando Roqueta RJ, Coral Blanco C, Lobo Satue A, Grasa Jordan MP (1996) Estudie de los fenomenos de estres y su relacion con variables psicopatologicas, clinicas e imminologicas en pacientes with alopecia areata. Actas Dermosifiologr 87: 597-609. 